\title{
Las marcas en los contextos de crisis. La empresa aguas de Mondariz y su respuesta a la crisis de los pepinos.
}

\author{
Montse VÁzQuez GeStal. \\ Universidade de Vigo. \\ mvgestal@uvigo.es \\ Ana Belén Fernández Souto. \\ Universidade de Vigo. \\ abfsouto@uvigo.es
}

\begin{abstract}
Resumen
Las crisis institucionales implican consecuencias en prácticamente todos los ámbitos de la vida, incluido el publicitario. En este caso, destacamos la respuesta de las marcas publicitarias españolas, concretamente Aguas de Mondariz, durante la crisis de los pepinos en el año 2011, que puso en entredicho la calidad de los productos españoles debido a las acusaciones de las autoridades alemanas.
\end{abstract}

Palabras clave: Crisis - Pepinos - Solidaridad - Comunicación - Publicidad.

Bands in crisis contexts. The company Aguas de Mondariz and its response to the crisis of cucumbers.

\begin{abstract}
Institutional crises entail consequences in practically all areas of life, including the advertising. In this case, we highlight the response of the Spanish advertising brands, specifically Aguas de Mondariz, during the crisis of the cucumbers in the year 2011, which put into question the quality of Spanish products due to the accusations of the German authorities.
\end{abstract}

Key Words: Crisis - cucumbers - solidarity - communication - advertising

Referencia normalizada:

Vázquez Gestal, M. y Fernández Souto, A. B. (2013) Las marcas en los contextos de crisis. La empresa agua de Mondariz y su respuesta a la crisis de los pepinos. Historia y Comunicación Social. Vol. $18 \mathrm{~N}^{\mathrm{o}}$ Especial Octubre. Págs. 207-218

\section{Sumario:}

1. Introducción. 2. Las fases de la crisis de los pepinos. 3. La empresa Aguas de Mondariz. 3.1. Aguas de Mondariz y sus valores comunicativos. 4. La campaña "Orgullosos de nuestros pepinos". 5. Conclusiones. 6. Bibliografía 


\section{Introducción}

La denominada "crisis de los pepinos" del año 2011 supuso para España no solo una crisis alimentaria e institucional, sino que tuvo consecuencias en muchos de los ámbitos de actuación cotidianos.

Las acusaciones iniciadas en el país germano, a raíz de la aparición de diversas intoxicaciones causadas por la bacteria Eschericchi coli enterohemorrágica (E. coli), sobre la culpabilidad de una partida de pepinos provenientes de España, derivaron en una serie de consecuencias que puso en entredicho la calidad no solo de los productos del sector hortifructícola español, sino también la de otros productos. Esto convertía una alarma sanitaria en algo mucho más global y con unas repercusiones económicas millonarias.

Esta crisis, protagonizada fundamentalmente por España y Alemania, se considera a la vez una crisis internacional y multi-institucional. Una crisis de origen sanitario pero cuya dimensión política magnificó su importancia desde el punto de vista mediático. No podemos verla solamente como una crisis sanitaria grave (ha llegado a causar la muerte y a ingresar en hospitales a decenas de personas por toda Europa) con un responsable, sino que la trascendencia política de la crisis (acusación de las autoridades alemanas y, posteriormente, europeas, contra los productos españoles y defensa del gobierno español de sus productos patrios) multiplicó su presencia en los medios, llegando incluso a conseguir en los diarios españoles más de 900 portadas en el mes de mayo del año 2011, lo cual se traduce en un alcance de casi 182 millones de impactos de audiencia y una cuantificación económica superior a 9 millones de euros, según se desprende del informe "E.Coli Pepinos cultivados en España"1.

Con una dimensión mediática de tal impacto y una cuantificación económica de tal envergadura, es lógico pensar que todos los sectores fueron conscientes de lo que significaba este problema, incluidos el resto de productos españoles y las marcas españolas que los sustentaban.

Así, dentro de este contexto, distintas marcas comerciales españolas salieron al rescate y defensa de la calidad de los productos españoles, convirtiendo una crisis de carácter internacional y multi- institucional en una oportunidad de negocio y una forma de restaurar el valor de lo "patrio" frente a ataques externos.

El uso de la comunicación y, concretamente, de la comunicación publicitaria para restaurar el valor de lo español es lo que pretendemos analizar en el presente artículo a través del análisis de la comunicación publicitaria utilizada por la marca gallega Aguas de Mondariz, que se apuntó a la defensa de los pepinos españoles utilizando para ello la reputación que como marca de calidad tiene a nivel internacional. 


\section{Las fases de la crisis de los pepinos}

La crisis se inicia en de mayo de 2011, concretamente el día 22, cuando el gobierno alemán emite un comunicado donde informa de un importante brote de la bacteria Eschericchi coli enterohemorrágica, con un elevado grupo de pacientes con el Síndrome Urémico Hemolítico (HUS). A mediados del mes de mayo, ingresan los primeros pacientes en hospitales del la zona norte alemana. Se confirmaron más de 1200 infecciones, de las que algo más de un tercio se concentraron en la zona de Hamburgo. Aparecen también casos en Dinamarca, Suecia, Reino Unido, Francia y Países Bajos. En los datos finales, unas 4000 infecciones, con cerca de mil casos de gravedad.

La primera acusación que se vierte hacia los pepinos españoles provienen de la senadora de Hamburgo, Cornelia Prüfer-Storcks ${ }^{2}$, y la Comisión Europea, sin ningún tipo de comprobación, alerta, desde su webs del origen del brote y señala a España como principal sospechosa.

Ante estas primeras acusaciones, el gobierno de España, por boca de la entonces Ministra de Medio Ambiente y Medio Rural y Marino, Rosa Aguilar, informa de la falta de pruebas para emitir esas acusaciones (Viúdez y Soler, 2011), elevando una queja ante Alemania y la Unión Europea. Por su parte, desde la comunidad andaluza, la más dañada por las acusaciones, la consejera de Agricultura y Pesca, Clara Aguilera, afirma que el daño causado al sector hortofrutícola andaluz era ya "incalculable" e "irrecuperable"(Varios, 2011).

El 27 de mayo, la Comisión Europea emite un comunicado reconociendo su precipitación ${ }^{3}$, pero ello no impide que otros países empiecen a vetar los productos españoles en sus mercados, caso de Rusia. Desde Alemania, Jürgen Thier-Kundke, del Instituto Federal de Evaluación de Riesgos (BFR), considera "muy comprensible que los agricultores españoles estén molestos", y entienden que hubo precipitación en la acusación a los pepinos españoles, pero entienden que fue un "problema de recepción" de la noticia puesto que las autoridades "nunca limitaron sus advertencias a un tipo de verdura ni a un país de procedencia”. Tampoco la Ministra Federal de Consumo, Ilse Aigner, ni el Instituto Robert Koch de Berlín dejaron en ningún momento de prevenir contra el consumo de lechugas, tomates y pepinos crudos de cualquier procedencia y, "en particular, en el norte de Alemania”(Gómez, 2011).

En España, las comparecencias de los responsables políticos y las gestiones a nivel internacional se suceden de forma ininterrumpida. Comparecen la ministra de Medio Ambiente, la de Sanidad y el Secretario de Estado de Medio Rural y Agua, que mantienen contactos con las principales comunidades autónomas afectadas y con la Agencia Española de Seguridad Alimentaria. Se suceden las declaraciones institucionales tranquilizadoras y se condena la irresponsabilidad de las autoridades alemanas apuntando la culpabilidad hacia España.

El 31 de mayo, la Comisión Europea emite una nota de prensa asegurando que los pepinos españoles ya no son sospechosos, tras habérseles realizado las pruebas perti- 
nentes. Alemania acabaría reconociendo que el brote procedía de una pequeña factoría de la Baja Sajonia y que nada tenían que ver los pepinos provenientes de España.

Sin embargo, las consecuencias fueron irreversibles para el sector español, la cosecha recogida ya no fue vendida y, ciñéndonos solo a la provincia de Almería, las exportaciones de hortalizas frescas en 2011 cayeron un 40\% comparado con el mismo mes del año anterior, lo que supuso unas pérdidas de casi un $48 \%$. A ello se añaden las pérdidas de puestos de trabajo.

Las autoridades españolas criticaron la actuación del Ministerio de Sanidad Alemán, barajando la posibilidad de solicitar medidas legales contra los acusadores, caso de la cooperativa malagueña Frunet (Martín-Arroyo y Lucio, 2011) quien presentó una demanda ante los tribunales de lo Contencioso Administrativo de Hamburgo contra las autoridades alemanas por el perjuicio generado a las empresas productoras en España, cifrado en más de un millón de euros.

\section{La empresa aguas de mondariz}

Con más de 150 años de historia a sus espaldas, la empresa Aguas de Mondariz incluye su actividad dentro del área de la alimentación y la restauración, y se extiende por más de 30 países de todo el mundo, incluyendo el mercado alemán.

Los manantiales de la empresa se encuentran en los términos gallegos de Mondariz y Mondariz Balneario, en la provincia de Pontevedra, concretamente en la cuenca hidrogeográfica del río Tea, afluente del Miño, y la historia de la localidad siempre ha girado alrededor de la explotación de sus aguas minero medicinales.

Diversos documentos relacionan esta localidad con la antigua villa romana de Búrbida, en ellos se indica también que los antiguos habitantes del Castillo del Sobroso conocían y utilizaban estas aguas en unas instalaciones destruidas en la Batalla de Uclés (siglo XII). El redescubrimiento de las aguas y su valor medicinal en el siglo XIX se debe al médico de la localidad, Domingo Blanco Lage, quién observó por primera vez el valor curativo de las aguas, al ver cómo sus vecinos las aplicaban en sus heridas dermatológicas, usándolas posteriormente con fines terapéuticos en el desarrollo de su profesión.

Los años de mayor esplendor llegaron con Enrique Peinador Vela y su familia. En el año 1873 se consigue la Declaración de Utilidad Pública del agua y en 1877 comienza el envasado del agua mineral. Durante muchos años la actividad de envasado se desarrolla paralelamente a la del Balneario, de cuyas aguas disfrutaron personajes ilustres del siglo XX español, como Isaac Peral y Echegaray, Arniches, Primo de Rivera, Castelao, W. Fernández Flórez, Castelar.... "Esto no es un balneario: es el Palacio de las Aguas" afirmó el Premio Nóbel José de Echegaray al conocer los efectos salutíferos de las aguas de Mondariz. 
Desde el punto de vista del reconocimiento internacional, la empresa cuenta con numerosos premios, medallas y distinciones que reconocen la calidad del producto, habida cuenta su historia y desarrollo. Reconocimientos internacionales entre los que destacamos el de la Exposición Universal de Barcelona, Bruselas y París; la Exposición Internacional de Madrid, Génova, Londres, Amsterdam, Amberes, Milán, Sevilla y Karlsbad, sin olvidar el Superior Taste Award (ITQI) del año 2012, siendo la primera y única empresa española que lo ha obtenido en dos ocasiones.

\subsection{Aguas de mondariz y sus valores comunicativos}

La construcción de una imagen fuerte y el valor de la comunicación para conseguirlo es algo que forma parte de la historia del Balneario de Mondariz y de sus aguas medicinales. Pero también para el negocio de la venta de aguas.

El Balneario necesitó desde sus orígenes asentar su imagen y para ello utilizó la prensa y la publicidad, pero también construyó sus publicaciones para diferenciarse del resto de balnearios e informar sobre sus aguas, servicios e instalaciones, tal y cómo relata Pérez Sánchez (2008: 267).

Desde la imprenta del Balneario se editaba todos los domingos de temporada, desde al año 1889, un semanario titulado La Temporada que se fue llenando de colaboraciones científicas, literarias o administrativas de sus ilustres visitantes: Murguía, Pondal, Emilia Pardo Bazán, Alfredo Vicenti, Emilio Castelar, Marcelo Macias o Isidro Parga Pondal, entre otros.

En 1899, los Hermanos Peinador publican un Album-guía titulado Las Aguas de Mondariz para obsequiar a sus amigos, la prensa nacional y extranjera, y a los favorecedores del Establecimiento minero-medicinal. En este caso se trataba de una lujosa publicación encargada a Alfredo Vicenti, con cubierta modernista y en la que además de planos, fotos e ilustraciones del establecimiento y alrededores, se presentaba un mapa del trazado de la red de carreteras y trenes y colaboraciones de autores como Echegaray, Celso García de la Riega o Isaac Pera.

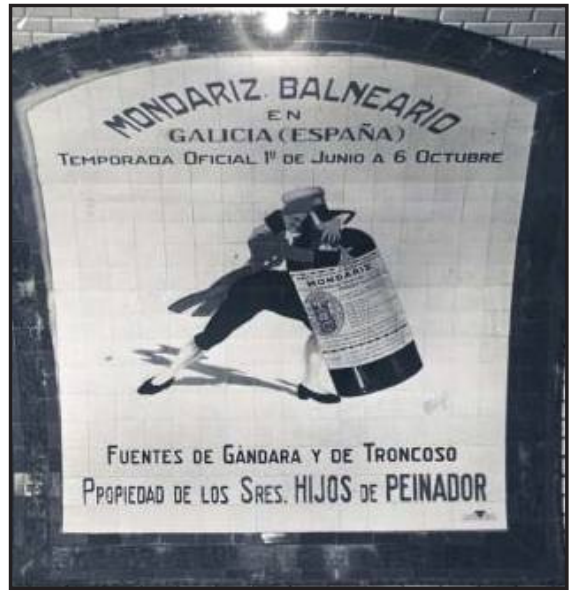

Historia y Comunicación Social

Vol. 18. No Esp. Octubre (2013) 207-218
Publicación continuada por otras, en forma de guía, traducidas incluso al inglés y francés y que contribuyeron a crear la imagen e identidad del Balneario. A ellas hay que sumar otras publicaciones posteriores destinadas tanto a la promoción del establecimiento balneario como al fomento de la cultura gallega.

A partir de los años veinte del pasado siglo, a la publicidad escrita se une la creación de la imagen publicitaria de Aguas de Mondariz por medio del diseño de carteles que aparecen en varias publicaciones periódicas y en espacios urbanos, como el metro de Madrid, donde un 
mural de azulejos, firmado por "Maga", representaba la característica etiqueta de las botellas. (Figura 1)

En el año 1929 aparece la imagen que ha perdurado hasta hoy. La protagonista de la imágenes ha sido siempre la célebre botella que mantuvo su austero diseño durante muchos años: de cristal verde oscuro con una etiqueta que, en palabras de Alfredo Vicenti "seduce por lo serio y sencillo" y "encarnan las ideas, puestas siempre en práctica de los señores Peinador, de fiar más en la positiva eficacia de las aguas que en presentaciones relumbrantes y en los ruidos, siempre efímeros, de la propaganda a gritos" (Buvette 2008: 278).

Desde ese primer diseño se ha ido evolucionado y actualizando esa imagen de los años 20 (Figura 2) que, en la actualidad, pervive en cada uno de los productos de Mondariz (Figura 3).
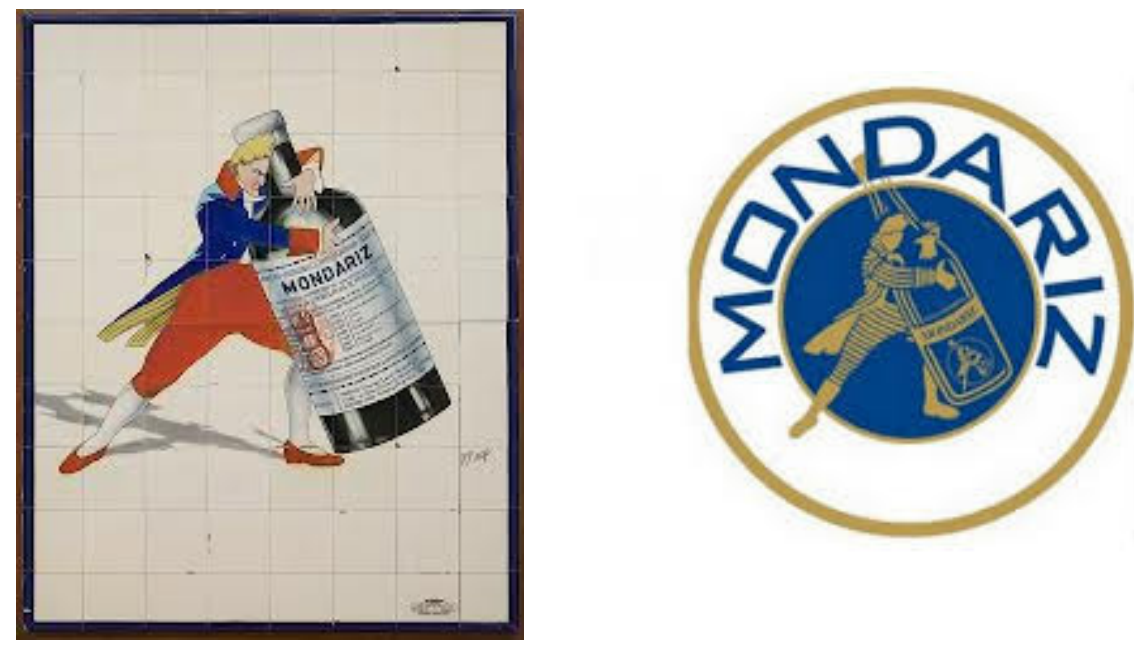

Desde el punto de vista comunicativo, Aguas de Mondariz siempre ha tenido un concepto asociado a la calidad pero, en sus inicios, la gente no tenía claro si dicha denominación se refería a una marca de agua o a algo medicinal.

A finales de los años 80, las dos marcas de agua de la empresa (Mondariz y Fuente del Val) tenían solamente el 1\% del mercado del agua, lejos de las cifras de principios del siglo XX, cuando Mondariz y Vichy Catalán eran líderes en el agua con gas (Solano Rodríguez-Losada, 2008: 36).

La estrategia de la marca por parte de la empresa siempre fue clara, dar prestigio a la marca, no entrar en la política de precios y comunicar los valores de prestigio y calidad.

El consumidor busca que el agua sea saludable y que la marca le ofrezca unas constantes ya que la lealtad a una marca de agua es bastante efímera y frágil por lo que la comunicación en general, y la publicidad en particular, pueden ayudar de manera 
importante. Tengamos en cuenta que hablamos de un mercado con gran número de marcas, con poca diferenciación entre ellas, que buscan situarse en conceptos de comunicación parecidos.

Una de las primeras campañas desarrolladas por la marca Aguas de Mondariz en la década de los 90 fue Cuanto más bebes más te gustas. En ella buscaba ofrecer un agua saludable que ayudaba a cuidarse diariamente, pero sin grandes artificios ni grandes promesas, al contrario, la mayor sencillez posible y el intento de seguir con esa imagen de calidad apoyada en el peso del pasado pero pensando también en el futuro.

Todo ese trabajo comienza a dar sus frutos y resultados. A mediados de la década de los 90, Aguas de Mondariz multiplicaba por cinco su facturación, a finales de dicha época comenzaban los trabajos de exportación de manera eficaz, consiguiendo pocos años después, en el año 2005, convertirse en la empresa española que más agua exportaba.

\section{La campaña "orgullosos de nuestros pepinos"}

El compromiso con la tierra y la sociedad de la que forma parte, Galicia, será otro de los grandes valores asociados a la imagen de Aguas de Mondariz, completando así aquellos de calidad, prestigio, sencillez, y la importancia del pasado para construir el futuro, destacados desde siempre por sus fundadores.

En 1915 aparecía, a iniciativa de Enrique Peinador, la revista ilustrada Mondariz. En la primera página de la publicación se resumía su filosofía: "Podíamos condensar en una sola frase los móviles que nos guían (...). Con decir que queremos hacer patria, saldríamos del paso" (Buvette 2008: 276). Es decir, para esta empresa y sus fundadores, la personalidad de su pueblo se acusaba en su capacidad de creación espiritual y ese valor, esa capacidad, era algo a destacar y a aplicar en su propia actividad.

Teniendo en cuenta estas circunstancias, entendemos el compromiso que esta empresa siempre ha demostrado con Galicia y la sociedad en la que se desarrolla, y que tiene incluso respuestas en sus actuaciones de patrocinio, centradas en actividades donde el valor del trabajo en equipo, la participación y el componente educativo, prevalecen sobre los resultados finales obtenidos o las expectativas cumplidas.

Aguas de Mondariz apoya al deporte y la cultura gallega con su aportación a equipos de ciclismo, remo, baloncesto, bandas de música, campeonatos escolares..., buscando así una diferenciación con otras marcas. No busca una presencia mediática importante a través de grandes equipos y deportes mayoritarios, pues eso no responde a su filosofía de vida, sino que busca apoyar desde la cercanía, haciendo ver que la empresa entiende que vive en una sociedad a la que debe su existencia y sin la que no podría desarrollarse. 
La importancia del origen, en este caso Galicia y los gallegos, y de participar activamente en su desarrollo, ha llevado a la empresa a defender su identidad en situaciones en las que consideraba necesario recordar la importancia de la tierra a la que uno pertenece, la denominación de origen o la procedencia ante descalificaciones estúpidas de quienes pretendían el insulto fácil. Entendemos que éstas son las cuestiones que subyacen en el origen de la campaña que desarrolla en el año 2010, como consecuencia de unas desafortunadas declaraciones de la diputada Rosa Díaz.

En febrero de ese año, la número uno de Unión Progreso y Democracia (partido que aspiraba a entrar por primera vez en el Congreso de los Diputados español, UPyD), Rosa Díez, era entrevistada en el canal $\mathrm{CNN}+$ por el periodista Iñaqui Gabilondo. En un momento de la entrevista Gabilondo le solicita que defina algunos políticos, el primero de ellos José Luis Rodríguez Zapatero, presidente del gobierno en aquel momento, a lo que Díaz contesta "podría ser gallego, en el sentido más peyorativo del término", prosigue Gabilondo: "Rajoy? Y contesta Rosa Díez: es gallego". Cabe explicar que una de las acepciones ya eliminadas del Diccionario de la Real Academia de la Lengua Española, establecía como sinónimo peyorativo de gallego el concepto de tonto ${ }^{4}$.

No es preciso señalar la repercusión que tuvieron sus palabras, sobre todo porque no era la primera vez que insultaba a los gallegos, teniendo en cuenta que la misma expresión la había usado ya unos meses antes con respecto al presidente de la Xunta de Galicia, Alberto Núñez Feijoó, (Clemente, 2010).

Las respuestas, ante tales declara-

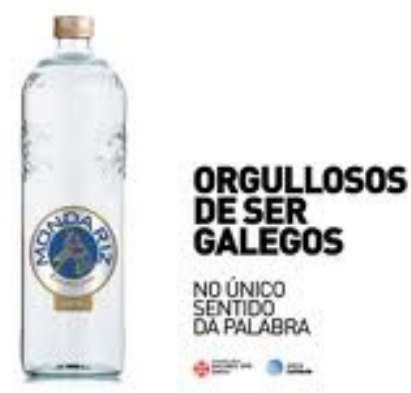
ciones, no se hicieron esperar desde los ámbitos políticos, culturales y sociales de Galicia, pero no fueron los únicos. La empresa Aguas de Mondariz decidió también destacar y defender su origen, el valor de ser gallego, al margen de acepciones varias que puedan aplicarse a su gentilicio, dejando claro que todo lo que es, lo que representa y lo que ha conseguido tiene mucho que ver con el hecho de ser gallego. (Figura 4)

En esta misma situación de defensa del origen, de las peculiaridades o particularidades que aporta el hecho de ser de un lugar determinado, entendemos la campaña que Aguas de Mondariz desarrolla dándole protagonismo al pepino español.

Creemos que, en este caso, se trata de defenderse ante una "agresión" distinta, no se trata del origen más cercano (Galicia) dentro del territorio geográfico español, o de las peculiaridades de cada territorio, sino que en este caso es una defensa más amplia, frente a un "enemigo" que desprestigia "lo español" lo que, en muchos casos, puede 
provocar un efecto de contagio a otros productos con el mismo origen, de hecho en el caso de la crisis de los pepinos ocurrió con otros producto hortofrutícolas españoles.

Aguas de Mondariz aprovechó su presencia en el mercado alemán y la concesión del Cristal Tase Award 2011, para dedicarle dicho premio al sector hortofrutícola español bajo el lema "Orgullosos de nuestros pepinos, porque han demostrado máximo nivel de calidad". La campaña fue desarrollada en español y alemán para dar a entender y demostrar una vez más que Aguas de Mondariz equiparaba su calidad -avalada por el premio internacional- con la del pepino español, puesta en duda en aquellas últimas semanas y demostrada después.

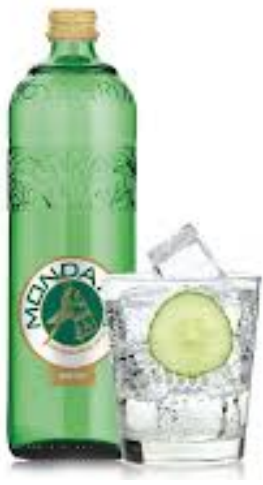

ORGULLOSOS DE NUESTROS PEPINOS

PORQUE HAN DEMOSTRADO MÁXIMO NIVEL DE CALIDAD

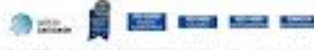

La empresa se solidarizaba con el producto atacado y lo apoyaba en un intento de sostener, demostrar y mostrar que la misma calidad que le es reconocida a ella en el contexto internacional, ella se la reconocía a los productos españoles. (Figura 5).

No fue la única acción comunicativa en defensa del producto español, sino que reforzaba una estrategia que habían protagonizado otras marcas españolas, caso de J. García Carrión ${ }^{5}$ quién, a través de su marca Don

Simón, había puesto en marcha una campaña de apoyo al pepino en la que, con cada litro de gazpacho de la marca Don Simón se regalaba un pepino, uno de los ingredientes de esta receta mediterránea, posicionándose al lado de los agricultores que habían sufrido las pérdidas derivadas de las acusaciones alemanas.

En el caso de Mondariz, se trataba de un producto alimentario (el agua) pero menos próximo que en el caso de Don Simón, por lo que resulta interesante la apuesta de Aguas Mondariz como empresa gallega, teniendo en cuenta además que en esta comunidad autónoma la producción del pepino es prácticamente inexistente y su comercialización más limitada que en otras zonas de la Península.
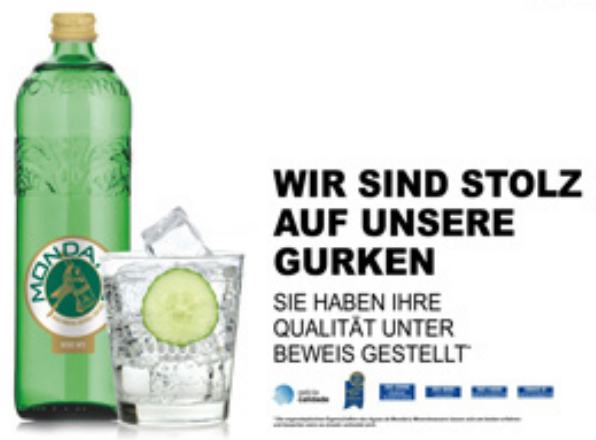

Destacar además que los productos de Mondariz se comercializan en más de treinta países en todo el mundo, por lo que la apuesta por este tipo de campaña podría resultar bastante arriesgada.

El lema de la campaña era "Orgullosos de nuestros pepinos porque han demostrado máximo nivel de calidad" y se tradujo al alemán WIR 
SIND STOLZ AUF UNSERE GURKEN sie haben ihre qualitat unter beweis geste1lt" (Figura 6)

La organización empresarial apostó por la defensa del pepino y por utilizarlo físicamente en la campaña a modo de sustituto de otras frutas que, habitualmente, pueden acompañar a un vaso de agua o refresco, caso de la naranja o el limón, tal y como se puede observar en la imagen utilizada para la campaña.

\section{Conclusiones}

La crisis de los pepinos entre España y Alemania fue inicialmente una crisis sanitaria que tuvo repercusiones no solo a nivel institucional sino también a nivel comunicativo y global.

Una de las repercusiones posibles era la mala calidad del pepino español, lo que podría derivar en una crisis comercial sobre otros productos españoles.

La crisis del pepino sirvió para descubrir nuevas posibilidades o nuevas facetas de comunicación para empresas y organizaciones.

En el caso del pepino español, la crisis causada por el envenenamiento de varios cientos de personas en Alemania y la acusación de ser provocada por este producto, sirvió para que otros productos, más o menos relacionados, reaccionasen en defensa del mismo, a través de su presencia en medios y del uso de estrategias de comunicación acertadas y originales.

La empresa de Aguas de Mondariz, de origen gallego, se ha caracterizado desde sus inicios por una defensa y orgullo de lo propio, Galicia. La defensa del territorio, de la denominación de origen como una de las razones de la calidad.

Esos valores de calidad le han sido reconocidos internacionalmente con la concesión de distintos distintivos.

La empresa gallega decidió usar esos valores, reconocidos internacionalmente, para avalar un producto denostado en un momento concreto.

Aguas de Mondariz sigue, en cierto modo, las directrices comunicativas que siempre ha desarrollado para sí misma: defender lo valores del producto y asociarlo a la calidad. La campaña Orgullosos de nuestros pepinos, busca asociar la calidad de la empresa gallega al producto hortofrutícola.

La unión de la marca con dicho producto en esta situación de crisis se resolvió de manera positiva, pues el consumidor percibió esa defensa de la calidad por parte de una empresa en quien confia desde hace años. 


\section{Bibliografía}

CONTRERAS, D. (2006). "La gestión de crisis en la comunicación organizacional: el caso de Chile". Anàlisis, no 34. Barcelona. P. 305-313.

GONZÁLEZ HERRERO, A. (1998). Marketing preventivo: la comunicación de crisis en la empresa. Barcelona: Bosch.

LOSADA DÍAZ, J. (2010). Comunicación en la gestión de crisis. Barcelona: UOC.

MITROFF, I. (2005). Why some companies emerge stronger and better from a crisis: 7 essential lessons for surviving disaster. New York: Amacon.

PÉREZ SÁNCHEZ, Y. (2008). "Imagen publicitaria de Mondariz" en Buvette (19082008). Cien años del Pabellón del Gándara. Mondariz: Fundación Mondariz Balneario. p. 260-286.

SOLANO RODRÍGUEZ-LOSADA, J. (2008). "Una marca de agua". En Buvette (1908-2008). 100 años del Pabellón del Gándara. Mondariz: Fundación Mondariz Balneario. p.34-40.

TAYLOR, M.; KENT, M. (2007). "Taxonomy of mediated crisis responses". Public Relations Review, 33. Michigan. p.140-146.

TÚÑEZ, M. (coord.) (2007): Comunicación preventiva. Planificación y ejecución de estrategias de información interna y externa ante situaciones de crisis. A Coruña: Net Biblo.

VVAA. (2008). Buvette (1908-2008). Cien años del Pabellón del Gándara. Mondariz: Fundación Mondariz Balneario.

XIFRA, J. (2005). "La gestión de conflictos potenciales como estrategia de comunicación corporativa: el caso Microsoft". ZER, nº 18. Bilbao. p. 67-81.

Artículos en publicaciones web:

CLEMENTE, E. (2010). "Clamor contra Rosa Díez por utilizar "gallego" para descalificar a Zapatero". http://www.lavozdegalicia.es/espana/2010/02/25/0003_8317708. $\mathrm{htm}$. [Consultado el 5 de septiembre de 2012].

GÓMEZ, J. (2011). "Son ya 14 los fallecidos por la cepa de E. Coli en Alemania". http://sociedad.elpais.com/sociedad/2011/05/30/actualidad/1306706404_850215. html. [Consultado el 5 de septiembre de 2012].

MARIÑO, H. (2010). "Zapatero es gallego en el sentido más peyorativo del término" http://www.publico.es/espana/297725/rosa-diez-zapatero-es-gallego-en-el-sentido-mas-peyorativo-del-termino . [Consultado el 5 de septiembre de 2012].

MARTÍN-ARROYO, J.; LUCIO, L. (2011). "Una cooperativa alemana demanda al gobierno de Hamburgo por la crisis del pepino".

http://sociedad.elpais.com/sociedad/2011/06/09/actualidad/1307570418_850215. html. [Consultado el 7 de agosto de 2012].

VIÚDEZ, J.; SOLER, M. (2011). "El gobierno afirma que no hay pruebas de la contaminación de pepinos se haya producido en España". http://sociedad.elpais.com/ sociedad/2011/05/27/actualidad/1306447207_850215.html. [Consultado el $30 \mathrm{de}$ julio de 2012]. 
VVAA (2010). "Rosa Diez afirma que no quiso ofender a nadie al llamar gallego a Zapatero". http://www.elmundo.es/elmundo/2010/02/25/espana/1267101302. html. [Consultado el 18 de agosto de 2012].

VVAA (2011). "La crisis del pepino provoca pérdidas cuantiosísimas a la agricultura española". http://sociedad.elpais.com/sociedad/2011/05/30/actualidad/1306706406_850215.html. [Consultado el 30 de julio de 2012].

\section{Notas}

1 Acceso Group. "E.Coli, Pepinos cultivados en España. Análisis de repercusión mediática". http:// www.slideshare.net/accesogroup/crisis-pepino-v3 . [10 de diciembre de 2011].

2 "Un análisis relaciona el brote infeccioso en Alemania con una partida de pepinos españoles" http:// www.elmundo.es/elmundosalud/2011/05/26/nutricion/1306408025.html. [Consultado el 15 de septiembre de 2012].

3 "Alemania exculpa a los pepinos españoles pero sigue sin venderlos". 31 de mayo de 2011. http:// www.elmundo.es/elmundo/2011/05/31/economia/1306865596.html. [Consultado el 4 de agosto de 2012].

$4 \mathrm{http} / /$ www.youtube.com/watch?v=HPgWFmnxDHk; Ver también, MARIÑO, H. "Zapatero es gallego en el sentido más peyorativo del término" http://www.publico.es/espana/297725/rosa-diez-zapatero-es-gallego-en-el-sentido-mas-peyorativo-del-termino [Consultado el 5 de septiembre de 2012]; "Rosa Diez afirma que no quiso ofender a nadie al llamar gallego a Zapatero". http://www. elmundo.es/elmundo/2010/02/25/espana/1267101302.html. [Consultado el 18 de agosto de 2012].

$5 \mathrm{http} / /$ www.garciacarrion.es/es/actualidad-detalle/don-simon-regala-un-pepino-con-gazpacho. [Consultado el 12 de mayo de 2012].

\section{Las autoras:}

Montse Vázquez Gestal, Doctora en Ciencias de la Información. Profesora invitada en universidades italianas, mexicanas y portuguesas. Docente en materias de Creatividad Publicitaria y Estrategias de la Actividad Publicitaria. Directora del grupo de investigación CP2 de la Universidad de Vigo e investigadora principal del grupo de investigación de la Xunta de Galicia: comunicación y turismo para minorías. Autora de artículos sobre creatividad publicitaria, imagen de marcas, tendencias creativas, marca-territorio.

Ana Belén Fernández Souto, Doctora en Publicidad y Relaciones Públicas. Profesora invitada en universidades mexicanas, uruguayas, brasileñas, costarricenses y portuguesas. Docente en materias como Planificación Estratégica de las Relaciones Públicas, Relaciones Públicas y Protocolo y Técnicas de las relaciones públicas. Autora de diversos libros y numerosos artículos sobre relaciones públicas, gestión de eventos, comunicación de crisis, organización, protocolo. 